\title{
Should positron emission tomography be the standard of care for non-invasive surveillance following cardiac transplantation?
}

\author{
Robert J. H. Miller, MD, ${ }^{\mathrm{a}}$ Jon A. Kobashigawa, MD, ${ }^{\mathrm{b}}$ and Daniel S. Berman, MD, \\ FACC $^{\mathrm{a}}$ \\ a Departments of Imaging and Medicine, Cedars-Sinai Medical Center, Los Angeles, CA \\ b Smidt Heart Institute, Cedars-Sinai Heart Institute, Cedars-Sinai Medical Center, Los Angeles, \\ CA
}

Received Oct 19, 2018; accepted Oct 26, 2018

doi: $10.1007 / \mathrm{s} 12350-018-01508-8$

The number of patients with end-stage heart failure has increased over the last decade and is expected to continue to rise. Cardiac transplant is the only established, cost-effective therapy for end-stage heart failure. ${ }^{1}$ Median survival following cardiac transplant is now greater than 13 years, and as a result many patients are now surviving until they develop cardiac allograft vasculopathy $(\mathrm{CAV}) .^{2}$ In patients who survive at least 5 years after transplant, CAV accounts for over a third of deaths, many of which occur suddenly. ${ }^{3} \mathrm{CAV}$ is also the most common indication for re-transplantation in patients who survive at least one year. ${ }^{4}$

CAV is characterized by diffuse arteriopathy involving the epicardial arteries and microvasculature. ${ }^{5}$ Traditionally the diagnosis of CAV has been made using invasive coronary angiography. ${ }^{6}$ Since the transplanted heart is denervated, most patients with CAV remain asymptomatic until they develop late disease. Given the important therapeutic and prognostic implications, cardiac transplant programs employ routine surveillance assessments. Many transplant programs utilize serial coronary angiography which carries a risk of bleeding,

Electronic supplementary material The online version of this article (https://doi.org/10.1007/s12350-018-01508-8) contains supplementary material, which is available to authorized users.

The authors of this article have provided a PowerPoint file, available for download at SpringerLink, which summarises the contents of the paper and is free for re-use at meetings and presentations. Search for the article DOI on SpringerLink.com.

Reprint requests: Daniel S. Berman, MD, FACC, Departments of Imaging and Medicine, Cedars-Sinai Medical Center, Room 1258, 8700 Beverly Boulevard, Los Angeles, CA 90048; bermand@cshs.org

J Nucl Cardiol 2019;26:655-9.

$1071-3581 / \$ 34.00$

Copyright (C) 2018 American Society of Nuclear Cardiology. stroke, and vascular injury. Intravascular ultrasound (IVUS) has been shown to be more sensitive for early disease, ${ }^{5}$ since it can measure coronary plaque volume and maximal intimal thickness (MIT) which has been associated with an increase in sudden death, myocardial infarction, and need for revascularization. ${ }^{7}$ However, the improved diagnostic accuracy comes at the expense of increased procedural risks and costs. ${ }^{8}$ Due to this limitation, non-invasive monitoring of CAV is becoming a standard component of surveillance post-transplantation.

There are several modalities currently used for noninvasive surveillance in cardiac transplant patients. Single photon emission computed tomography (SPECT) is commonly used around the world to assess for CAV. However, SPECT has suboptimal sensitivity in the setting of diffuse disease which is the typical pattern seen in CAV. The diagnostic sensitivity has been reported to be as low as $14 \%$ for identifying a stenosis $\geq 70 \%$. Dobutamine stress echocardiogram has been used because of its wide availability and lack of ionizing radiation. However, the sensitivity is $7 \%$ for any $\mathrm{CAV}$ and only $28 \%$ for CAV grade 2 or $3 .{ }^{10}$ Cardiac CT angiogram has reasonable sensitivity $(81 \%)$ and specificity $(75 \%)$ for IVUS-defined CAV, however there is a paucity of prognostic data available. ${ }^{11}$ Positron emission tomography (PET) has several advantages over other non-invasive modalities. PET allows more accurate assessment of regional differences in flow by providing routine measurement of myocardial blood flow (MBF). Additionally, rest and stress MBF can be compared to determine myocardial flow reserve (MFR) which has independent diagnostic and prognostic utility. Finally, there is a growing body of evidence regarding the prognostic significance of PET findings which may help physicians identify patients who should be considered for cardiac re-transplantation. 


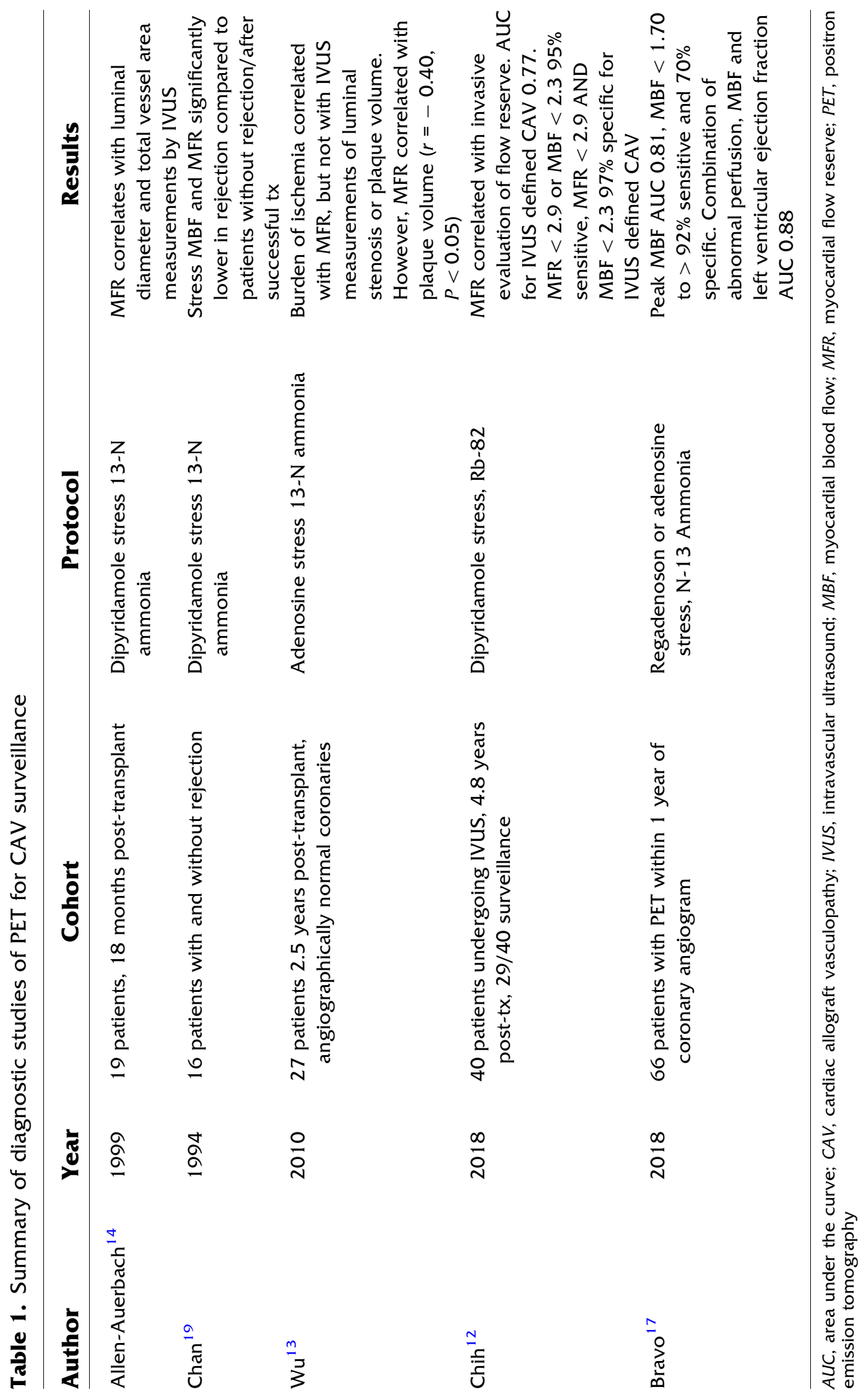




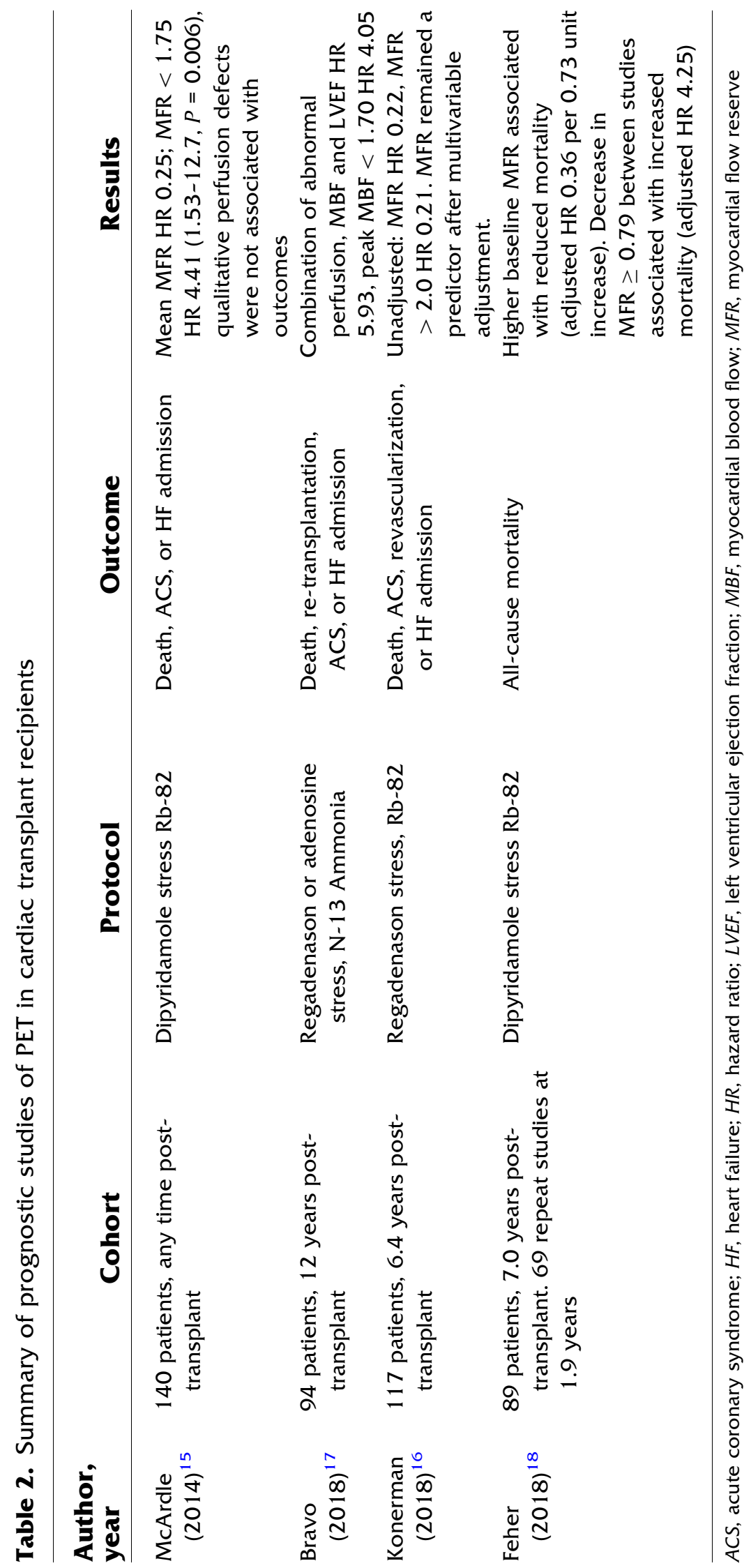


Table 1 outlines studies assessing the diagnostic performance of PET with MBF assessment. PET is most commonly compared IVUS since PET is capable of identifying disease that may be missed with routine invasive coronary angiography. Due to the increased sensitivity, corrected MFR, MBF, and coronary vascular resistance (CVR, stress systolic blood pressure/stress MBF) are more closely correlated with IVUS then conventional angiography with area under the curve of $0.77-0.81$ vs $0.55-0.67 .{ }^{12}$ MFR is inversely related to plaque volume as assessed by IVUS $(r=-0.40$, $P<0.05) .{ }^{13}$ Additionally, baseline MFR corrected for the rate-pressure product correlates with change in lumen area observed by IVUS after 18 months of follow-up. ${ }^{14}$ The presence of abnormal MBF or CVR results in a sensitivity of $97 \%$ for the presence of IVUSdefined CAV, and the presence of both features increases the specificity to $97 \% .^{12}$ This diagnostic accuracy is superior to alternate non-invasive modalities, and may allow physicians to better target immunosuppressive adjustments in patients with early CAV.

In addition to improved diagnostic accuracy, PET may provide prognostic information as outlined in Table 2. McArdle et al. demonstrated that MFR $<1.75$ was associated with a more than 4-fold increase in the risk of death, acute coronary syndrome (ACS), or heart failure (HF) admission. ${ }^{15} \mathrm{~A}$ separate study demonstrated that MFR $>2.0$ was associated with a favorable prognosis [hazard ratio (HR) 0.22] for the combined outcome of death, re-transplantation, ACS, or HF admission. ${ }^{16}$ Combining regional perfusion abnormalities, left ventricular ejection, and MBF can stratify patients into groups with a five-fold difference in rates of death, retransplantation, ACS, or HF admission. ${ }^{17}$ Feher et al. investigated the prognostic significance of serial PET assessments and found that higher baseline MFR associated with reduced all-cause mortality (adjusted HR 0.36 per 0.73 unit increase). ${ }^{18}$ However, decrease in MFR $\geq 0.79$ (adjusted HR 4.25) or stress MBF $\geq 0.80$ (adjusted HR 5.01) between studies had the greatest association with increased all-cause mortality suggesting a prominent role for serial assessments. ${ }^{18}$ While external validation studies are needed, these studies demonstrate that PET offers potentially useful prognostic information which cannot be obtained with alternate modalities.

To facilitate more uniform application of PET for CAV surveillance two practical considerations require clarification. Correction of MBF for rate-pressure product (RPP) has been variably applied in published studies. While there is a close correlation between resting MBF and RPP in patients with acute rejection $(r=0.77),{ }^{19}$ the correlation between stress MBF and RPP is modest in patients without active rejection $(r=0.25) .{ }^{18}$ Bravo et al. found that uncorrected MFR was numerically, but not statistically, superior to corrected MFR (area under the curve [AUC] 0.80 vs 0.72). ${ }^{17}$ Until this question is definitively answered, it seems that utilizing uncorrected MBF may be a prudent approach. ${ }^{20}$ Determining the optimal parameters cut-offs and combinations also requires prospective validation. One of the only studies to compare the diagnostic accuracy of MBF to MFR found superior accuracy with stress MBF (AUC 0.89 compared to 0.80 ). ${ }^{17}$ Combining parameters will allow physicians to optimize either the sensitivity of specificity of the test based on the combination chosen. ${ }^{12}$ However, both of these questions could be efficiently resolved by validation studies facilitated by the broader application of PET for CAV surveillance.

PET is clearly the most sensitive non-invasive modality for identifying early CAV, which classically has only been detected by IVUS. Additionally, the prognostic information available from PET could allow transplant programs to identify patients with CAV at the highest risk. These patients could be assessed and listed for cardiac re-transplantation, the only definitive therapy for end-stage CAV, a process which could take months or years. Early identification of those patients may prevent the development of refractory $\mathrm{HF}$, requiring multiple hospitalizations with associated costs, or preempt sudden death. Given these advantages PET should become the standard of care, when available, for the non-invasive surveillance of CAV.

\section{Disclosure}

The work was supported in part by the Dr. Miriam and Sheldon Adelson Medical Research Foundation. Dr. Miller receives funding support from the Arthur JE Child Fellowship grant.

\section{References}

1. Kilic A, Phillips G, Chimanji N, Sai-Sudhakar CB, Hasan A, Higgins RSD, et al. Cost comparison between heart transplantation and left ventricular assist device implantation. J Cardiac Fail. 2014;20:S84.

2. Lund LH, Khush KK, Cherikh WS, Goldfarb S, Kucheryavaya AY, Levvey BJ, et al. The registry of the international society for heart and lung transplantation: thirty-fourth adult heart transplantation report-2017; focus theme: allograft ischemic time. J Heart Lung Transplant. 2017;36:1037-46.

3. Taylor DO, Stehlik J, Edwards LB, Aurora P, Christie JD, Dobbels F, et al. Registry of the International Society for Heart and Lung Transplantation: twenty-sixth official adult heart transplant report-2009. J Heart Lung Transplant. 2009;28:1007-22.

4. Lund LH, Edwards LB, Kucheryavaya AY, Benden C, Christie JD, Dipchand AI, et al. The Registry of the International Society for Heart and Lung Transplantation: Thirty-first Official Adult Heart Transplant Report-2014; Focus Theme: Retransplantation. J Heart Lung Transplant. 2014;33:996-1008. 
5. Pollack A, Nazif T, Mancini D, Weisz G. Detection and imaging of cardiac allograft vasculopathy. JACC Cardiovasc Imaging. 2013;6:613-23.

6. Mehra MR, Crespo-Leiro MG, Dipchand A, Ensminger SM, Hiemann NE, Kobashigawa JA, et al. International Society for Heart and Lung Transplantation working formulation of a standardized nomenclature for cardiac allograft vasculopathy-2010. J Heart Lung Transplant. 2010;29:717-27.

7. Mehra MR, Ventura HO, Stapleton DD, Smart FW, Collins TC, Ramee SR. Presence of severe intimal thickening by intravascular ultrasonography predicts cardiac events in cardiac allograft vasculopathy. J Heart Lung Transplant. 1995;14:632-9.

8. Stone GW, Maehara A, Lansky AJ, de Bruyne B, Cristea E, Mintz GS, et al. A prospective natural-history study of coronary atherosclerosis. N Engl J Med. 2011;364:226-35.

9. Thompson D, Koster MJ, Wagner RH, Heroux A, Barron JT. Single photon emission computed tomography myocardial perfusion imaging to detect cardiac allograft vasculopathy. Eur Heart J Cardiovasc Imaging. 2012;13:271-75.

10. Chirakarnjanakorn S, Starling RC, Popovic ZB, Griffin BP, Desai MY. Dobutamine stress echocardiography during follow-up surveillance in heart transplant patients: diagnostic accuracy and predictors of outcomes. J Heart Lung Transplant. 2015;34:710-7.

11. Wever-Pinzon O, Romero J, Kelesidis I, Wever-Pinzon J, Manrique $\mathrm{C}$, Budge $\mathrm{D}$, et al. Coronary computed tomography angiography for the detection of cardiac allograft vasculopathy: a meta-analysis of prospective trials. J Am Coll Cardiol. 2014;63:1992-2004.

12. Chih S, Chong AY, Erthal F, deKemp RA, Davies RA, Stadnick E, et al. PET assessment of epicardial intimal disease and microvascular dysfunction in cardiac allograft vasculopathy. J Am Coll Cardiol. 2018;71:1444-56.

13. Wu Y-W, Chen Y-H, Wang S-S, Jui H-Y, Yen R-F, Tzen K-Y, et al. PET assessment of myocardial perfusion reserve inversely correlates with intravascular ultrasound findings in angiographically normal cardiac transplant recipients. J Nucl Med. 2010;51:906-12.

14. Allen-Auerbach M, Schöder H, Johnson J, Kofoed K, Einhorn K, Phelps ME, et al. Relationship between coronary function by positron emission tomography and temporal changes in morphology by intravascular ultrasound (IVUS) in transplant recipients. J Heart Lung Transplant. 1999;18:211-9.

15. Mc Ardle BA, Davies RA, Chen L, Small GR, Ruddy TD, Dwivedi $\mathrm{G}$, et al. Prognostic value of rubidium- 82 positron emission tomography in patients after heart transplant. Circulation. 2014;7:930-7.

16. Konerman MC, Lazarus JJ, Weinberg RL, Shah RV, Ghannam M, Hummel SL, et al. Reduced myocardial flow reserve by positron emission tomography predicts cardiovascular events after cardiac transplantation. Circ Heart Fail. 2018;11:e004473.

17. Bravo PE, Bergmark BA, Vita T, Taqueti VR, Gupta A, Seidelmann S, et al. Diagnostic and prognostic value of myocardial blood flow quantification as non-invasive indicator of cardiac allograft vasculopathy. Eur Heart J. 2018;39:316-23.

18. Feher A, Srivastava A, Quail MA, Boutagy NE, Khanna P, Wilson $\mathrm{L}$, et al. Serial assessment of coronary flow reserve by rubidium- 82 positron emission tomography predicts mortality in heart transplant recipients. JACC Cardiovasc Imaging. 2018. https://doi.org/ 10.1016/j.jcmg.2018.08.025.

19. Chan SY, Kobashigawa J, Stevenson LW, Brownfield E, Brunken RC, Schelbert HR. Myocardial blood flow at rest and during pharmacological vasodilation in cardiac transplants during and after successful treatment of rejection. Circulation. 1994;90:20412.

20. Gewirtz H. Serial PET measurements of myocardial blood flow for prognosis assessment in heart transplant patients: the forest and the trees. JACC. 2018. https://doi.org/10.1016/j.jcmg.2018.09.001. 